\title{
EDUCAÇÃO DO CAMPO E AS LIMITAÇÕES NO ENSINO DE ECOLOGIA: ANÁLISE DE DUAS ESCOLAS NO MUNICÍPIO DE BATALHA (PI) ${ }^{1}$
}

\author{
Field education and the importance of ecology education: analysis of two schools in the municipality of Batalha (PI)
}

Raimundo Nonato de Sousa Silva ${ }^{2}$

Sandra Regina de Sousa Cardoso ${ }^{3}$

\begin{abstract}
RESUMO: Devido à ação predadora do homem em relação à natureza, os recursos provenientes do meio vêm dando sinais de esgotamento, ficando cada vez mais evidente, a necessidade de mudanças nessa relação de desafeto. Neste cenário de mudanças, a escola surge com destaque, pois é o espaço formativo mais presente na sociedade, depois do contexto familiar e, o ensino de Ecologia é uma ferramenta disponível que deve abordar os meios pelos quais eleve a consciência das pessoas, ampliando as condições de melhorias para sociedade e o meio ambiente. Nesse sentido, este estudo objetivou pesquisar sobre a importância do ensino de Ecologia para duas escolas campesinas no município de Batalha (PI). Assim, analisou-se tal ensino na formação básica vivenciado nas escolas municipais Joana D'arc Castelo Branco e Gayoso de Almendra para a formação de consciência mais elevada acerca das questões ambientais. O trabalho com caráter qualitativo/quantitativo pesquisou 143 alunos dos anos finais do Ensino Fundamental, através da aplicação de questionário. O mesmo evidenciou que o ensino de Ecologia difundido nas escolas é muito aquém do necessário. Percebeu-se que, a estrutura pedagógica limita-se a desenvolver um ensino simplista, gerando consequências tangíveis no processo de formação dos estudantes e o desenvolvimento de ações sustentáveis. $\mathrm{O}$ estudo conclui que as escolas estudadas devem assumir outra postura mediante ao tema Ecologia, e, tão somente através de uma nova forma de trabalhar essa área do ensino, promoverá uma elevação da consciência ecológica dos estudantes às mesmas estarão assumido seu papel de destaque ao qual têm como potencial.
\end{abstract}

Palavras-chave: Ecologia. Escolas campesinas. Sujeito ecológico. Questão ambiental.

\begin{abstract}
Due to the predatory action of man in relation to nature, the resources coming from the environment have been showing signs of exhaustion, becoming increasingly evident, the need for changes in this relationship of disaffection. In this scenario of changes, the school appears prominently, as it is the formative space most present in society, after the family context, and the teaching of Ecology is an available tool that must address the means by which it raises people's awareness, expanding improvement conditions for society and the environment. In this sense, this study aimed to research on the importance of teaching Ecology to two rural schools in the municipality of Batalha (PI). Thus, it was analyzed such teaching in the basic formation experienced in the municipal schools Joana D'arc Castelo Branco and Gayoso de Almendra for the formation of a higher awareness about environmental issues. The qualitative/quantitative work surveyed 143 students in the final years of elementary school, through the application of a questionnaire. The
\end{abstract}

\footnotetext{
1 Trabalho vinculado ao Curso de Licenciatura em Educação do Campo da UFPI, através de Monografia de conclusão de curso, realizado entre 2018 e 2019.

${ }^{2}$ Graduando do Curso de Licenciatura em Educação do Campo (LEdoC) pela Universidade Federal do Piauí (UFPI). E-mail: nonatosousa9ph@gmail.com

${ }^{3}$ Doutora em Agronomia (Proteção de Plantas) pela Universidade Estadual Paulista Júlio de Mesquita Filho (UNESP). Professora do Curso de Licenciatura em Educação do Campo (LEdoC) da Universidade Federal do Piauí (UFPI), Campus Ministro Petrônio Portella (CMPP), em Teresina (PI). E-mail: sandra.cardoso@ufpi.edu.br
} 
same showed that the teaching of Ecology disseminated in schools is far below what is necessary. It was noticed that the pedagogical structure is limited to developing a simplistic teaching, generating tangible consequences in the process of training students and the development of sustainable actions. The study concludes that the schools studied must take a different stance through the theme of Ecology, and, only through a new way of working in this area of education, will promote an elevation of the ecological awareness of students to them, their prominent role will be assumed to which have the potential.

Keywords: Ecology. Peasant schools. Ecological subject. Environmental issue.

\section{CONSIDERAÇÕES INICIAIS}

É notória a preocupação de parte da população atual com o meio ambiente, devido às causas e consequências que estão levando o planeta e seus habitantes a um desequilíbrio ecológico sem precedentes. Paralelo a isso, também é causa de destaque do tema, os limites que o ambiente impõe a mais marcante característica do modelo societário atual: a economia. A ecologia refere-se à capacidade de recuperação e reprodução dos ecossistemas (resiliência) em face de agressões naturais ou antrópicas, e foi quem primeiro afirmou sobre a finitude dos recursos naturais frente ao uso predatório (NASCIMENTO, 2012).

Assim, com os desafios cada vez mais frequentes ligados a esse tema, sejam eles de caráter ecológico ou econômico, têm surgido à necessidade da reinvenção do homem no modo de se relacionar com os recursos naturais. Nessa esfera, a escola, como espaço formativo, emerge com destaque nas possibilidades de intervir positivamente frente a esse cenário. De fato, a educação, como forma de transformação das condições socioambientais não pode se deter em ações pontuais e uma visão fragmentada, na qual o homem é visto como externo ao meio, cabendo-lhe a função de explorador, controlador e fiscalizador (SOUZA, 2009).

Dando créditos a esta questão, os Parâmetros Curriculares Nacionais (PCN) (BRASIL, 1998), apresentam que a principal função do trabalho com o tema Meio Ambiente é contribuir para a formação de cidadãos conscientes, aptos a decidir e atuar na realidade socioambiental de um modo comprometido com a vida global. Para isso, faz-se necessário que, para além de informações e conceitos, a escola se proponha a trabalhar com atitudes, com formação de valores, com o ensino e aprendizagem de procedimentos que reverencie a vida. Ou seja, que seja superado o grande desafio da educação, ocorrendo à compreensão de que homem e ambiente estão interligados, o homem é parte integrante do meio.

Embora a educação brasileira disponha de documentos que colaborem para disseminação de conhecimentos relacionados com o meio ambiente na escola, a exemplos dos PCN, acredita-se 
que a Ecologia ainda é pouco trabalhada nesse espaço, sobretudo, no Ensino Fundamental, tornando necessário que o ambiente escolar tome outras medidas e torne-se lócus de processos educativos que tenham dimensão ambiental como foco, pois é na fase da infância e da adolescência que são colhidas as primeiras sensações, impressões e sentimentos do viver (TIRIBA, 2010).

Com base no exposto, fica evidente que trabalhar temas relacionados com o Meio Ambiente propõe discussões sobre a sociedade, bem como, sobre a necessidade de sua mudança comportamental, como, por exemplo: redução do consumo, reciclar, reutilizar e outros que resultem na transformação da relação sociedade humana-natureza.

Frente a essa questão, espera-se e deseja-se que a escola campesina assuma seu protagonismo de relacionar teoria e prática, de assumir uma proposta educativa relacionando o que se ensina com o que se vivencia no cotidiano do estudante, da família e da comunidade. É preciso refletir sobre o papel socioambiental da escola. Nesse sentido, este estudo objetivou pesquisar sobre a importância do ensino de Ecologia em duas escolas campesinas no município de Batalha (PI). Teve como questões norteadoras: Quais ferramentas e estratégias estão sendo utilizadas para o processo do ensino e aprendizagem acerca do tema? O ensino de Ecologia está sendo contextualizado coma realidade local? Ele está contribuindo para elevação da consciência dos estudantes, levando-os a compreensão de pertença ao meio e à prática de atitudes responsáveis?

\section{ECOLOGIA: SUA IMPORTÂNCIA NO ENSINO BÁSICO}

De acordo com Odum; Barrett (2008), Ecologia é o estudo da estrutura e do funcionamento da natureza. Diante de sua complexidade, a Ecologia tem grande importância para o equilíbrio da terra, quando esta assume o papel de reverter ou, pelo menos, de resistir à visão dominante que a espécie humana tem assumido frente à vida no planeta.

Para Townsend; Begon; Harper (2010, p. 16) faz-se necessário o entendimento e uso correto do termo Ecologia, sobre isso afirmam:

Atualmente, a ecologia é um assunto sobre o qual quase todo mundo tem prestado atenção e a maioria das pessoas consideram importante - mesmo quando elas não conhecem o significado exato do termo. Não pode haver dúvida de que ela é importante, mas ela se torna ainda mais crucial quando compreendemos o que ela é e como estudá-la.

Conforme as preposições dos autores, as pessoas não devem estudar Ecologia só porque é um tema de grande relevância no meio social nos dias atuais, mas, deve, de fato, ser compreendido o motivo, pelo qual, se estuda e, principalmente, os meios pelos quais devem se dá o estudo para 
que, através dessa prática, se eleve a consciência dos sujeitos e estes sejam capazes de promover relações afetivas com o meio.

Nessa perspectiva, os PCN (BRASIL, 1998) orientam que a escola precisa trilhar por um caminho mais ecológico e que não basta que os alunos tirem notas 10 nas provas, mas, ainda assim, joguem lixo na rua, que pesquem peixes-fêmeas prontas para reproduzir ou que toquem fogo nas florestas indiscriminadamente, mas, que estes precisam se sentir responsáveis pelo mundo em que vivem. Nesse contexto, Carvalho; Steil (2008) mostram ser necessário que os educadores, juntamente de seus alunos, construam em conjunto, o processo de desenvolvimento de um sujeito ecológico. Para os autores, sujeito ecológico é aquele com capacidade e sensibilidade para identificar e compreender os problemas ambientais, mobilizando-se e comprometendo-se com as decisões relacionadas ao ambiente equilibrado.

Silva (2012) afirma que, quando o termo Ecologia não é bem trabalhado ao longo do ensino básico, resulta em concepções errôneas e proporciona a ineficiência da sensibilização de uma sociedade ecológica, uma vez que os Livros Didáticos (LD) abordam os temas pontualmente, podendo provocar uma imagem limitada aos alunos e assim, obstruindo um conhecimento pleno.

Aprender ecologiano no ensino básico permite ao aluno compreender a forma como o ser humano deve se relacionar com o meio ambiente natural, além de ampliar seu entendimento sobre o mundo vivo, para isso, no Ensino Fundamental os estudantes devem ser estimulados a observar e conhecer os fenômenos biológicos, os seres vivos, sua saúde e conhecer a utilização dos produtos científicos (BRASIL, 1998; 2002). Neste sentido, a Ecologia assume um papel de buscar refletir e resolver os problemas do meio ambiente e têm como princípio, a responsabilização de reconhecer as carências de todos os seres vivos (MOTOKANE, 2000).

É importante compreender que o ensino de Ecologia não trata apenas de assuntos diretamente ecológicos, como algumas propostas curriculares propõem, mas se preocupa também, com situações que promovam a formação crítica social das pessoas, fazendo elas, conhecedoras dos seus direitos e deveres frente às questões ambientais, serem pessoas mais humanizadas, capazes de se posicionar diante a questões de injustiça social (LIGNANI; AZEVEDO, 2013).

Mariani Júnior (2008) enfatiza que o trabalho realizado ao longo da escolarização básica deve, por exemplo, criar condições para que o aluno, diante de uma notícia ou fato ocorrido em seu meio, seja capaz de opinar criticamente a respeito dos temas ligados a essa área. Neste contexto, ao transmitir corretamente os conhecimentos de Ecologia nessa fase, a escola cria possibilidades para que os adolescentes e os jovens se tornem pessoas mais críticas e conscientes do papel a assumir na sociedade. Sejam capazes de se relacionar com uma postura mais harmônica com as outras comunidades de vida que compõem à casa comum (o planeta terra). 
Os PCN (BRASIL, 1998) apontam ainda, que as questões ambientais se encontram intimamente ligadas a outros sujeitos do meio social, a exemplo, a política e a economia que podem ser alterados, uma vez que a sociedade esteja engajada em promover uma ideia de ambiente saudável e igualitário. Com isso, o ensino de Ecologia, trabalhado em Ciências e Biologia tem grande relevância para contextualizar corretamente o termo, suas aplicações e fundamentações teóricas (SILVA, 2012).

\section{EDUCAÇÃO DO CAMPO NESSE CONTEXTO}

A Educação do Campo propõe um modelo de educação diretamente relacionado às especificidades dos sujeitos a quem se destina e dos contextos nos quais a escola está inserida, sem, no entanto, perder de vista, as funções tradicionais da escola: socialização das novas gerações e acesso aos conhecimentos historicamente acumulados pela humanidade. Desse modo, faz-se necessária uma imersão da instituição escolar na compreensão da realidade, de modo a perceber as contradições existentes e comprometer-se com a melhoria da qualidade de vida das pessoas por ela atendidas.

Tal proposição, remete à importância de um ensino contextualizado histórica, social e politicamente, que leve os alunos a reconhecerem as possibilidades e as limitações, próprias e da comunidade, bem como, da sociedade, de forma geral, problematizando-as e refletindo sobre as formas de intervenção que qualifiquem a vida individual e da coletividade. Nesse sentido, trazer para o centro do debate escolar a questão da relação ser humano e natureza é fundamental, tendo em vista, o caos que a desarmonia desta relação tem gerado.

A profecia “olhos de fogo”, relatada por uma Índia Cree, há mais de 210 anos, em que anunciou: "Um dia a terra vai adoecer. Os pássaros cairão do céu, os mares vão escurecer e os peixes aparecerão mortos nas correntezas dos rios", pode se concretizar num futuro bem próximo, e porque não dizer, já vem se acontecendo. Basta olhar as catástrofes naturais que estão acontecendo todos os dias, nos quatro cantos da terra, conforme anunciou a velha índia.

Denunciar o quanto o ser humano tem andado em contramão com a natureza, não é difícil, basta refletir sobre a porção de leis instituídas nos últimos tempos, no sentido de frear/impor limites em relação ao uso dos bens que ela dispõe. Este fato aponta que o ser humano tem se preocupado muito pouco em protegê-la, pois se há leis regulamentando o uso hoje, é porque muito já foi feito de modo irracional e imprudente (SILVA; SILVA, 2010), de tal modo, que a população humana atual já sente os efeitos negativos que tais atitudes causam. 
Para Tiriba (2010), o homem acreditou durante muitos séculos que a natureza era infinita e, dessa forma, as escolas formais passaram a ensinar as crianças que essa natureza existia em benefício exclusivo do ser humano, fato propulsor para o uso exagerado dela.

É válido ressaltar que, nesse percurso de séculos, em que o sujeito moderno foi desenvolvendo o hábito de dominância da natureza, uma pequena parcela espalhada no planeta, fez uso racional dos recursos provenientes da "mãe natureza", como assim eles chamam. Dentre esses povos, estão incluídos: os Indígenas, quilombolas, povos tradicionais, ribeirinhos, povos da floresta, entre outros, que têm o planeta terra como um ser vivo; e, os seres humanos como um membro de um todo complexo e, certamente por esse fato a Educação do Campo deve se basear não apenas no ensino promovido pelo meio formal da educação, mas deve se valer também, dos conhecimentos tradicionalmente desenvolvidos por seus progenitores (CALDART, 2012).

Mattos (2007) aponta que houve um tempo no qual se acreditava que os recursos ambientais eram abundantes e que nunca iriam acabar. Assim, não se via necessidade de preserválos. O valor atribuído ao meio ambiente era zero, ou seja, era considerado como bem gratuito, que não entrava na contabilidade econômica, apesar de ser usado na produção de bens e serviços.

Conforme esse entendimento, percebe-se a ganância econômica do ser humano, ao longo da história, que, cego por esta ganância, chega a ferir seu próprio habitat, gerando condições negativas que ameaçam todas as formas de vida do planeta. Nos trilhos dessa história, e depois de se encontrar cercado por estas anomalias, o homem começa a ver os bens naturais com outros olhos. Diante desse contexto, a fim de evitar o risco do uso excessivo e indiscriminado dos recursos naturais e sua completa degradação, ficou clara a necessidade de se atribuir valor positivo aos recursos ambientais. Por fim, a valoração econômica ambiental tornou-se imprescindível ao desenvolvimento das bases econômicas para o estabelecimento de políticas ambientais, conforme nos afirma Maia (2002).

Para Santos (2018), o pensar e o agir de modo sustentável passa pela tomada de consciência dos cidadãos. As proposições do autor mostram que ações sustentáveis provavelmente aconteçam em massa, na medida em que se realize um trabalho integral na sociedade, propondo reflexão sobre as problemáticas ambientais, possibilitando uma tomada de consciência capaz de influir diretamente em atitudes ecologicamente corretas.

Diante da questão, configuram-se de relevante importância, trabalhos integrais e interdisciplinares realizados nas escolas, desde o início da educação primária, perpassando por toda a vida acadêmica dos indivíduos humanos. O espaço escolar talvez seja o único, nesse momento, capaz de propagar em nível maior essa mensagem de sustentabilidade. Assim, a escola, sobretudo, a do campo deve assumir o desafio de difundir para as crianças e as jovens, modos sustentáveis de 
relacionamento entre o homem e a natureza, visando assegurar o uso sustentável dos recursos naturais pelos alunos e seus familiares, tendo em vista, serem estes recursos, a base de suas atividades primárias (ROSSET, 2017).

Nesse sentido, as escolas campesinas devem desenhar alternativas capazes de transformar homens e mulheres, adultos e crianças, em sujeitos mais ecológicos, e, portanto, se fundamentar no argumento de Tiriba (2010), de que para uma tomada de consciência ecológica, faz-se necessário que as escolas, logo em sua fase inicial de ensino, adotem um caminho capaz de sensibilizar as crianças a reconhecerem o valor intrínseco da flora, da fauna e, assim, de todos os ecossistemas.

\section{ASPECTOS METODOLÓGICOS}

O estudo foi realizado em duas escolas municipais em Batalha (PI), Escola Joana D'arc Castelo Branco [1] e Escola Gayoso de Almendra [2]. A primeira situada na localidade Caraíbas II, zona rural; e a segunda, na zona urbana deste município, porém, a maioria dos estudantes é proveniente de comunidade rurais periféricas da cidade. Ambas trabalham com a Educação Infantil e Ensino Fundamental completo. A escolha das escolas ocorreu fundamentalmente pelo grande vínculo do público atendido com o campo, elemento de grande importância mediante a proposta do estudo Além disso, somou-se o fato de que dispõem de horta e aceitaram voluntariamente participar da pesquisa.

O uso de duas amostras (uma do espaço rural e outra no urbano) se deve a intenção de analisar se as metodologias adotadas frente ao tema em questão, se diferenciam de uma escola para outra. Pois, para muitos, ainda existe uma visão superficial de que o ensino adotado nas escolas da cidade se sobressai àquele desenvolvido no campo.

A pesquisa foi realizada no período de setembro a novembro de 2018 e teve caráter qualiquantitativo. Este modelo preocupa-se em analisar e interpretar aspectos profundos, descrevendo a complexidade do comportamento humano. Fornece análise detalhada sobre as investigações, hábitos, atitudes e tendências de comportamentos (LAKATOS; MARCONI, 2011).

Para isso, pesquisou-se também, na literatura específica, teóricos que discutem a temática e os aspectos legais que garantem seu uso nas escolas, a fim de apropriar-se de conhecimentos que dizem respeito a Ecologia e o seu ensino na Educação Básica.

A adoção da pesquisa qualiquantitativa justifica-se pela compreensão de que ela traz a possibilidade de resultados eficientes, sendo que o seu uso determina o contato diretamente com o objeto estudado e permite a utilização de técnicas muito importantes. Dentre elas, foi realizado 
a aplicação de questionário semi-estruturado, com a finalidade de diagnosticar o conhecimento da amostra a respeito do tema estudado.

Os sujeitos envolvidos na pesquisa foram discentes dos anos finais do Ensino Fundamental das duas escolas estudadas, totalizando 143 alunos, sendo 78 na escola [1] e 65 na escola [2]. Ainda a respeito do público entrevistado, esse foi selecionado através da lista de frequência de cada turma, sendo adotado como critério de participação, os números ímpares.

Anterior à aplicação do questionário, foi explicado aos participantes à natureza e os objetivos da pesquisa, sendo a autorização formalizada por meio de Termo de Consentimento Livre e Esclarecido (TCLE). Além disso, os participantes não tiveram sua identidade revelada e a pesquisa não envolveu nenhum tipo de riscos (físicos, legais, biológicos, químicos) sendo seu objetivo apenas a verificação do conhecimento. Após coleta, os dados foram analisados descritivamente.

\section{EXPOSIÇÃO E DISCUSSÃO DOS RESULTADOS}

A pesquisa foi realizada com estudantes do $6^{\circ}$ ao $9^{\circ}$ ano do Ensino Fundamental, com idade entre 11 e17 anos, pertencentes a duas escolas do município de Batalha (PI). Na Escola Joana D’arc Castelo Branco, 37\% dos estudantes questionados pertence ao sexo feminino e $63 \%$ ao sexo masculino. Já na Escola Gayoso de Almendra, os números são de 41\% e 59\% para sexo feminino e masculino, respectivamente, e a soma de todos os entrevistados, totaliza 143 participantes.

Sendo o estudo da Ecologia o tema central da pesquisa, inicialmente, os estudantes foram questionados sobre a compreensão do conceito de Ecologia. A maioria (cerca de 70\%) dos estudantes da escola Gayoso de Almendra apontaram para opção correta, comparado com apenas $38 \%$ dos estudantes da escola Joana D’arc Castelo Branco (Figura 1). Os demais estudantes apontaram para alternativas restritas apenas a fatos pontuais aplicados no dia a dia pela escola e pela mídia, como, por exemplo: plantas, animais, natureza e o campo.

Os estudantes também foram examinados sobre afinidade com a ciência Ecológica, como os conhecimentos que ela trata se relacionam com o cotidiano das pessoas e com o meio natural. As respostas indicam que $41 \%$ e $48 \%$ dos estudantes da Escola Joana D'árc Castelo Branco e Escola Gayoso de Almendra, respectivamente, apontam gostar dos conteúdos abordados pela Ecologia. Contudo 43\% dos estudantes da primeira escola e cerca de $20 \%$ da segunda, afirmam não gostar, enquanto os demais gostam, especialmente, quando se realiza aulas de campo (Figura $02)$. 
Figura 1: Conceito de ecologia na concepção dos estudantes das escolas estudadas.
Figura 2: Respostas dos estudantes para o questionamento sobre afinidade com o estudo da ecologia.

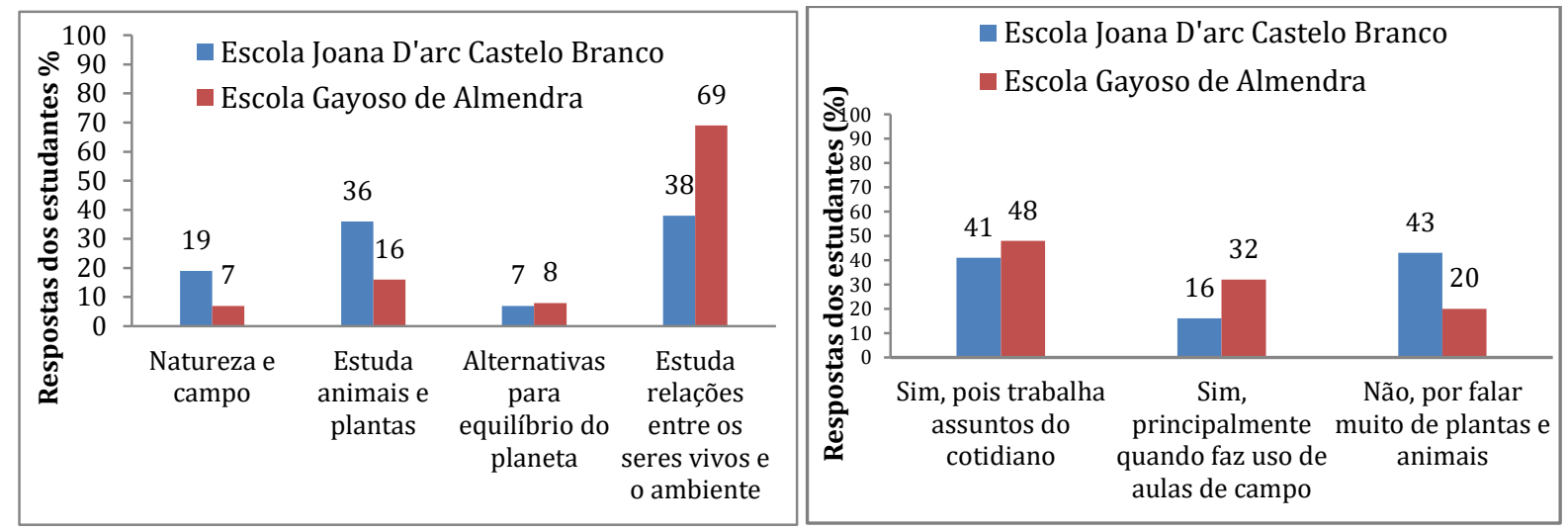

Fonte: Acervo dos autores (2019)

Acerca do questionamento sobre conceito de ecologia, cabe aqui, reiterar o que enfatizam os autores Townsend; Begon; Harper (2010, p. 16), sobre a superficialidade que é dada aos assuntos ecológicos.

Atualmente, a ecologia é um assunto sobre o qual quase todo mundo tem prestado atenção e a maioria das pessoas considera importante - mesmo quando elas não conhecem o significado exato do termo. Não pode haver dúvida de que ela é importante, mas ela se torna ainda mais crucial quando compreendemos o que ela é e como estudá-la.

Os propositores desse pensamento evidenciam a necessidade das pessoas compreenderem o termo "ecologia" corretamente, para que possam assumir postura responsável nas relações com o meio.

Para Souza; Azevedo (2016), a superficialidade do ensino limita as pessoas a compreenderem o real significado ontológico das coisas, o que acarreta em tomadas de decisões erradas, porém, entendidas como certas, assumindo assim, a alienação das pessoas. Fazendo uso do entendimento dos autores a respeito do ensino, o conhecimento mostrado pela maioria dos alunos a respeito da Ecologia mostra ser muito limitado, podendo assim, gerar sérias consequências nas atitudes diárias desses indivíduos.

É importante destacar que, as escolas do campo, embora cercadas por desafios, dispõem de grandes potenciais a respeito do ensino de Ecologia, visto que têm um espaço natural a sua disposição para realizar o elo entre a teoria e a pratica, dando sentido real ao aprendizado. A esse respeito, Silva; Lima (2016) esclarecem que faz-se necessário, na Educação do Campo, práticas educativas prazerosas, atraentes e relacionadas às vivências cotidianas dos educandos, despertandoos para valorização do conhecimento e do campo, reconhecendo o valor da educação para as 
transformações do meio em que vive. Na concepção de Freire (1996), a educação é um processo de encontro entre interlocutores, que, ao conhecer a significação da realidade, tem na práxis, o poder para transformá-la.

Para que a educação realmente aconteça em sua essência é necessário que os alunos consigam elevar a sua consciência, através dos estudos, fato que acontece quando o estudante é capaz de fazer ligações dos assuntos transmitidos com a realidade do cotidiano e, para além disso, efetive ações capazes de gerar o bem (SOUZA; AZEVEDO, 2016). Ao relacionar a reflexão que trazem os autores, com a Ecologia, os estudantes têm a elevação da consciência nesta área quando ao estudar os assuntos escolares ligados à vida são capazes de fazer conexão desses conhecimentos com a realidade vivida em seu meio, como, por exemplo: uso racional da água, do solo e das florestas, buscando meios de mudar ou, pelo menos, minimizar o desgaste destes.

Sobre o comprometimento da escola em ensinar Ecologia, na percepção dos estudantes, conforme Figura 2, foi revelado através da pesquisa que, 37\% dos alunos da escola [1] e 41\% da escola [2] consideram insatisfatória a forma como essas instituições de ensino vêm trabalhando o tema (Figura 3). Muito embora a maioria dos estudantes entenda que os conhecimentos de Ecologia estão sendo transmitidos satisfatoriamente, o questionário não ofertou possibilidade para que apontassem as estratégias e metodologias utilizadas, ou mesmo, justificarem sua resposta.

Contudo, quando foram questionados sobre os espaços utilizados para realização das aulas de Ecologia, a maioria dos estudantes, em ambas as escolas destaca que os conteúdos da área são trabalhados apenas dentro da sala de aula (Figura 4).

Figura 3: Respostas dos estudantes sobre o questionamento: sua escola estar preocupada em ensinar os conhecimentos de Ecologia.
Figura 4: Respostas dos discentes para o questionamento: aonde são realizadas as aulas relacionadas à Ecologia?

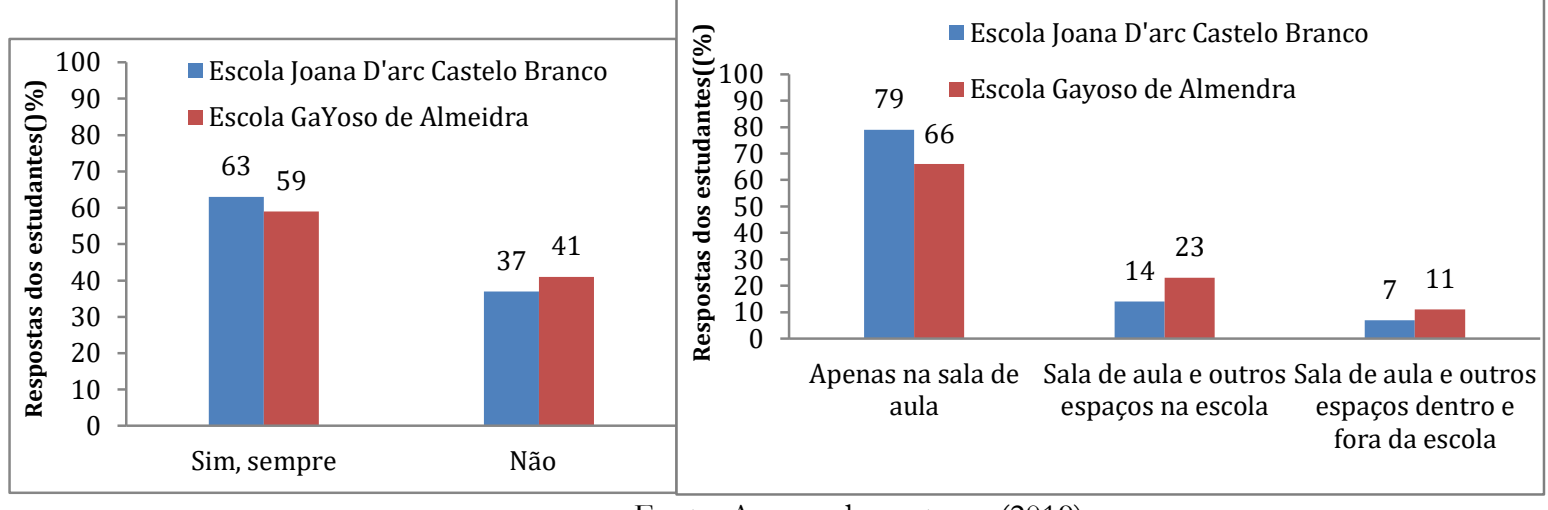

Fonte: Acervo dos autores (2019)

A respeito do comprometimento das escolas em desenvolverem momentos coerentes aos temas ligados à Ecologia, vale frisar que, estar intrinsecamente ligado às habilidades e altivez de 
cada escola. É preciso promover aulas interessantes, para que os alunos se enxerguem como sujeitos dentro das relações ecológicas e não percebam a Ecologia apenas como assuntos superficiais pautados em discussões teóricas estritamente ancoradas pelo Livro Didático (LD).

Uma forma interessante e íntegra de se tratar Ecologia nas escolas de formação básica perpassa obrigatoriamente pela contextualização. Sobre esta questão, Cribb (2010) enfatiza que a Ecologia deve ser tratada a partir de uma matriz que conceba a educação como elemento de transformação social, apoiada no diálogo e no exercício da cidadania. Comportamentos ambientalmente "corretos" devem ser aprendidos na prática, no cotidiano da vida escolar, contribuindo para a formação de cidadãos responsáveis. Para tal, é preciso entender e reconhecer a Ecologia como a ciência da interação (seres vivos e fatores abióticos) e as condições de existência da vida, e, portanto, há necessariamente uma relação de interdependência entre organismos e o meio onde vivem e do qual são parte integrante.

Nos tempos atuais, a Ecologia vem sendo considerado um campo de grande prestígio e importância (MOTOKANE; TRIVELATO, 1999). É uma ciência em plena expansão e, portanto, deve-se constantemente também expandir as metodologias de seu ensino, permitindo mudanças pedagógicas em todos os níveis escolares e que sejam significativas, pois sua sistematização e conhecimento permitiu reconhecimento maior do homem acerca do ambiente (MACIEL; GÜLLICH; LIMA, 2018). Nesse contexto, Brando (2010) enfatiza a Ecologia como interação, sendo desafiador para um saber fragmentado compreender esse enfoque ecológico, exigindo a necessidade de reforçar o pensamento sistêmico para que organismos e sistemas biológicos sejam percebidos como ricas relações de interações.

O dinamismo da prática pedagógica é o fator primordial do processo de ensino aprendizagem e as estratégias quanto ao local de produção do conhecimento são elementos substancialmente importantes desse processo (ANDRADE; FERNANDES, 2016). Assim, são inúmeras as possibilidades de se trabalhar questões atuais e urgentes na escola para formação de pessoas conscientes do seu papel no ecossistema. Definitivamente, trabalhar Ecologia apenas numa perspectiva de sala de aula, não somente reduz a importância da mesma, como compromete severamente o prazer do aprendizado, dificultando a apropriação do conhecimento acerca do homem, do ambiente e da interação e dependência entre ambos.

Considera-se de grande importância o trabalho com aulas de campo, através do estudo das interações ecológicas e biodiversidade local, práticas de florestamento e reflorestamento, produção de mudas, ou seja, criando possibilidades para prática de ações, a exemplos dessas citadas, a fim de que o aluno se veja como um agente dentro dos processos ecológicos. Em se tratando de escolas campesinas, inclusive, a agricultura praticada nas comunidades, como a horta escolar, pode 
ser um excelente espaço de discussão e contextualização. Porque não fazer uso desses e de outros espaços, dentro e fora da escola para se trabalhar Ecologia e as questões ambientais atuais?

Para Martins (2008), quando o ensino rompe as barreiras da sala de aula para que haja troca de informações provenientes do ambiente natural, o campo, este passa a ser multi, inter e trans disciplinar, promovendo aos sujeitos, conhecimentos do todo e não restrito unicamente à sala de aula. Conforme o pensamento do autor e as grandes reflexões das obras de Paulo Freire (1996; 2000), quando o ensino perpassa os muros da escola, o conhecimento passa a ser muito mais significativo, pois os alunos têm contato com os objetos em estudo e estes passam ter significado em suas vidas. Acredita-se que a reflexão relatada acima, pode ser ainda mais significativa, quando se remonta ao tema da Ecologia, pois ao sair do espaço físico da sala de aula, o professor tem muitos elementos práticos para enriquecer o aprendizado.

A educação tem real significância para o aprendizado, quando consegue fazer relação entre o objeto estudado e a sua realidade no dia a dia (FREIRE, 2000). Assim, cabe à escola e os docentes buscar a relação dos conteúdos presentes na grade curricular com a realidade em que o aluno estar inserido (LIMA; MELO, 2015). O ensino promovido pela escola deve está centrado na realidade dos alunos, para que eles sejam os protagonistas no processo. Para isso, os conteúdos trabalhados devem dialogar com problematizações criadas em sala de aula. De acordo com Duarte; Oliveira; Domingos (2018, p. 700):

Problematizar não é criar problemas, mas buscar através do diálogo, levantar questionamentos sobre situações problemáticas no intuito de incentivar o pensamento e a reflexão acerca das questões ligadas ao contexto social que se quer mudar por meio da conscientização e da ação.

Mediante o contexto dos problemas ambientais, a questão do lixo é presente na maioria das cidades brasileiras. Quando questionados se antes de descartar lixo, os estudantes refletem como poderiam reutilizar essa matéria-prima. Esses demonstraram não dar atenção merecida ao problema, que pode ser minimizado, quando se faz a reutilização de matéria-prima, sempre que possível, antes de descartá-la. A esse respeito, apenas 33\% e 36\%dos estudantes de ambas as escolas, concomitantemente, mostram não realizar essa reflexão, enquanto os demais ou refletem em raras situações ou jamais têm esse pensamento (Figura 5).

Outro ponto presente no questionário aplicado foi à indagação sobre o tipo de paisagem natural (bioma) da região. Para esse questionamento, a Figura 6 mostra que, para ambas as escolas, um percentual muito baixo e semelhante de estudantes responderam habitar na região semiárida, sendo essa a realidade do município. 
Figura 5: Respostas dos alunos para o questionamento: antes de descartar lixo refletem de como poderiam reutilizar essa matéria prima?

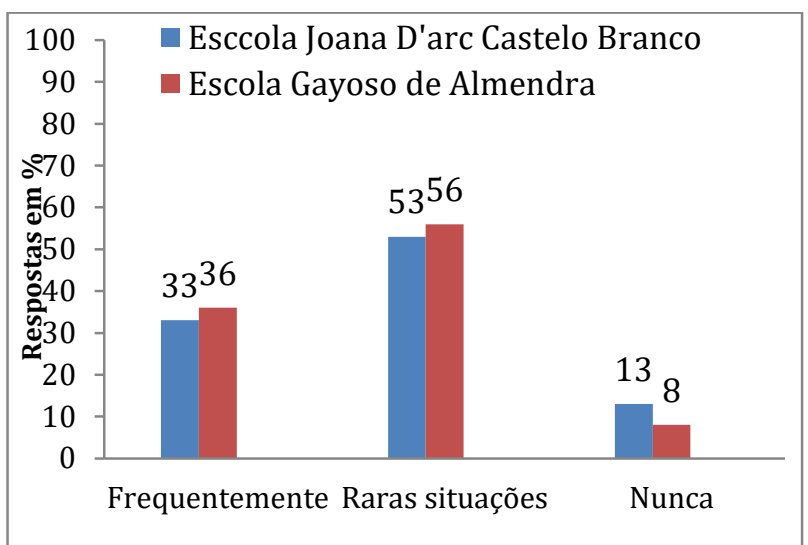

Figura 6: Respostas dos alunos para o questionamento: mediante as condições naturais de nossa região, sobretudo com relação à quantidade de chuvas e umidade, como ela se classifica?

Fonte: Acervo dos autores (2019)

Os problemas causados pelos resíduos sólidos cada vez mais aumentam, gerando danos aos seres vivos. Mediante esse cenário, é necessário que a sociedade adote medidas de redução e destino adequado do lixo, pois, além dos danos, os custos para a recuperação de áreas ambientalmente degradadas são elevados e torna-se mais barato preservar do que regenerar danos ambientais (OLIVEIRA; CASTRO, 2007).

Conforme o pensamento de Castro (2009), as questões ambientais que estão inseridas dentro do ensino de Ecologia, devem ter uma abordagem sistêmica e transversal na escola. A autora elenca ainda, que quando a escola trabalha de modo a sensibilizar os estudantes sobre o gerenciamento correto do lixo produzido pelos seres humanos, logo proporciona a percepção das relações mútuas dos fatos e eles começam a ter uma visão integral do mundo em que vivem, ampliando as condições de intervenções positivas no meio ambiente por estes indivíduos.

Souza; Azevedo (2016) apontam que, quando o estudante é capaz de fazer ligações dos assuntos transmitidos com a realidade do cotidiano e para, além disso, efetiva ação capaz da promoção social, define-se isso como “elevação da consciência humana”. No entanto, os sujeitos só irão desenvolver esse nível de consciência de modo massificador, se, por sua vez, tiverem a oportunidade de problematizações dessas questões no ambiente escolar, pois no momento que esses não têm a oportunidade de reflexões mais profunda a esse respeito, dificilmente terão consciência do que é certo ou errado nas suas ações do dia a dia.

Os dados acima mostram o baixo índice de jovens que se mostram tocados pela causa ambiental em questão, evidenciando que a maioria não pensa como poderiam reutilizar a matériaprima, antes de descartá-la. Fazendo uso das colaborações de Souza; Azevedo (2016), entende-se que a sociedade acadêmica ainda precisa caminhar mais e melhor para alcançar o desenvolvimento 
de uma maior consciência quanto ao tema, que reflita na realização de atitudes, comportamentos e ações no dia a dia, que sejam capazes de mudar o cenário de desgaste natural existente.

A percepção dos estudantes ainda é mais grave, quando trata do ecossistema onde habitam, pois ficou evidenciado no estudo, que os estudantes não conhecem a realidade onde estão inseridos, no que diz respeito ao bioma da região. É preciso despertar o interesse e a curiosidade para a questão e embora pareça ser simples, merece destaque, tendo em vista que, é a partir do conhecimento da realidade, que o sujeito pode elevar sua consciência e, inclusive, planejar e executar ações de convivência e permaneça nesse local.

Nesse caso, a região que as escolas estão situadas, de acordo com suas características físico-climáticas e biológicas, é denominada como região semiárida, sendo definida por Teixeira (2016), como região que apresenta característica físico-climática ímpar em seu ecossistema, que é o índice de pluviosidade baixa, menor de $800 \mathrm{~mm}$ ao ano. Este autor ainda apresenta elementos ligados à natureza, que são predominantes no semiárido: o período de chuva se restringe a três ou quatro meses durante o ano, intensidade de sol quase todos os dias do ano, a temperatura varia entre $23^{\circ} \mathrm{C}$ e $27^{\circ} \mathrm{C}$, o solo é rochoso, arenoso e raso, que, somado ao clima da região, é apontado por estudiosos como propenso à desertificação.

Mediante às especificidades implícitas no contexto da região semiárida, é clara a importância de ações pautadas na realidade local, a fim de manter o bioma estável para as futuras gerações. O que ressalta a importância das escolas encararem o assunto com maior compromisso.

Outra questão observada, a partir dos dados levantados é a limitada percepção dos estudantes em relação à biodiversidade. Ficou evidente a falta de conhecimento a respeito do bioma local e das consequências que vem sofrendo, sobretudo, pela ação humana. Quando interrogados sobre as espécies vegetais e animais que estão diminuindo na região, cerca de $80 \%$ dos estudantes não souberam informar sobre os vegetais e também, a maioria não soube apontar exemplos de animais. Uma minoria citou alguns nomes de espécies vegetais e animais, sendo elas: aroeira, cedro, pau Brasil, pau d'árco, jatobá (vegetais); e onça, veado, tatu, alguns pássaros e cobras (animais).

Os dados configuram que os alunos têm pouco conhecimento sobre a biodiversidade local da fauna e da flora. Ver-se isso claramente, quando listam na maioria aquelas espécies trazidas como exemplares nos LD. Contudo, cabe dizer que muitas espécies não apenas estão desaparecendo, mas correm o risco de extinção, ou mesmo, já foram extintas. O desconhecimento sobre a diversidade de espécies pode ocasionar baixo ou nenhum empenho na defesa por conservação e preservação dessas espécies Conforme Sadava et al. (2009), dentre as causas antrópicas de extinção das espécies, tem-se: destruição e fragmentação dos habitats, introdução de espécies exóticas e mudanças climáticas. 
A intensificação dos problemas ambientais tem despertado uma postura reflexiva da sociedade moderna para a conservação da biodiversidade (SILVEIRA; STUANI; CONFORTIN, 2014). Contudo, de acordo com Orozco (2017), a questão econômica desperta muito mais preocupação do que a grande destruição da diversidade biológica e a crise ecológica existente.

Guimarães (2005) sugere que, no contexto da educação, deve-se ter mais consciência e responsabilidade, para que possamos conviver com as demais espécies. Conforme Roos; Becker (2012), a degradação ambiental provocada pelas atividades do homem, afeta as condições de sobrevivência das espécies, põem em risco as populações de plantas e, consequentemente, de animais presentes no ambiente.

É preciso o homem reverter o quadro atual de degradação e de perdas das espécies, modificando sua maneira de relacionar com os recursos naturais. Nesse processo, a educação deve contribuir para que essa mudança aconteça de modo contínuo e ações concretas possam emergir. Contudo, de acordo com Boof (2009), o homem só realiza ações ecológicas corretas no dia a dia, se tiver a capacidade crítica para se situar com visão de mundo ampla e reflita sobre a interação necessária entre os seres vivos.

Portanto, a escola tem papel fundamental nesse contexto, cabendo aos profissionais da educação aprender mais e melhor, maximizando o aprendizado dos conteúdos, através de metodologias variadas no âmbito da Ecologia, já que esta é considerada de grande responsabilidade sobre a natureza e as condições de vida das espécies presentes.

\section{CONSIDERAÇÕES FINAIS}

Ao analisar os dados diagnosticados na pesquisa sobre os conhecimentos dos alunos a respeito do tema Ecologia e o ambiente que estão inseridos, entende-se que as instituições de ensino pesquisadas apresentam problemas no processo de ensino e aprendizagem no que diz respeito às questões ecológicas. Percebe-se, a carência de estratégias e ferramentas de ensino capazes de promover uma aprendizagem mais eficiente, possibilitando aos estudantes, leituras mais amplas de mundo, sendo essa, necessária para o surgimento de ações sustentáveis no cotidiano.

Entretanto, mesmo sabendo das fragilidades que as escolas do campo têm, principalmente, frente à questão estrutural, é possível o uso de estratégias adequadas para melhorar o ensino de Ecologia, pois o espaço campesino dispõe de vários ambientes que permitem vivenciar na prática os conteúdos teóricos estudados. Contudo, é preciso empenho da escola em discutir os aspectos ecológicos e ambientais localizados, a partir do cotidiano dos estudantes, mas também, de forma contextualizada com o todo, ou seja, de forma globalizada. 
O trabalho mostra que frente à importância do assunto e com as potencialidades que as escolas têm, estas precisam melhorar a forma de trabalhar a Ecologia, pois os dados levantados revelam que o modelo adotado deixa grandes lacunas na aprendizagem e na postura cotidiana dos envolvidos. Assim, o ensino de Ecologia no contexto campesino deve ser melhor trabalhado, não apenas pela relevância dos aspectos socioeconômicos e ambientais, mas, pelo fato de que, se for realmente compreendido, pode efetivamente contribuir para elevar a consciência dos sujeitos, sendo estes capazes de promover relações mais harmônicas entre si com o meio e trilhar um caminho consciente e responsável frente à relação homem/natureza.

\section{REFERÊNCIAS}

ANDRADE, Jailton dos Santos; FERNANDES, Silvia Aparecida de Souza. A importância da educação contextualizada para o desenvolvimento do semiárido. Revista NERA, Presidente Prudente, ano 19, nº 34, p. 157-178, 2016.

BRANDO, Fernanda da Rocha. Proposta didática para o Ensino Médio de Biologia: as relações ecológicas no cerrado. 2010. 217 f. Tese (Doutorado) - Faculdade de Ciências.

Universidade Estadual Paulista, Bauru, 2010. Disponível em:

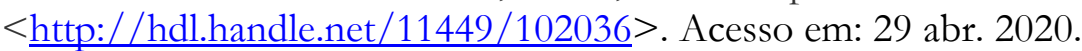

BRASIL. Secretaria de Educação Fundamental. Parâmetros Curriculares Nacionais: terceiro e quarto ciclos do Ensino Fundamental. Ciências Naturais. Brasília: MEC/SEF, 1998.

BRASIL. Decreto no 4.074, de 4 de janeiro de 2002. Diário Oficial [da] República Federativa do Brasil, Poder Executivo, Brasília, DF, 8 jan. 2002.

BOFF, Leonardo. A opção Terra: a solução para a Terra não cai do céu. Rio de Janeiro: Record, 2009.

CALDART, Roseli Salete. Pedagogia do movimento Sem Terra: escola é mais que escola. 2. Petrópolis: Vozes 2012.

CARVALHO, Isabel Cristiana Moura; STEIL, Carlos Alberto. A sacralização da natureza e a 'naturalização' do sagrado: aportes teóricos para a compreensão dos entrecruzamentos entre saúde, ecologia e espiritualidade. Ambiente \& Sociedade. Campinas, v. 11, n. 2, p. 289-305, 2008.

CASTRO, Maria Aparecida de. A reciclagem no contexto escolar. 2009, p. 01-29. Disponível em: < http://www.diaadiaeducacao.pr.gov.br/portals/pde/arquivos/448-4.pdf >. Acesso em: 14 abr. 2020.

CRIBB, Sandra Lucia de Souza. Contribuições da Educação Ambiental e Horta Escolar na Promoção de Melhorias ao Ensino, à Saúde e ao Ambiente. Rev. Eletr. do Mestr. Profis. em Ensino, Saúde e Ambiente, Rio Grande do Sul, v. 3, n. 1, p. 42-60. 2010. 
DUARTE, Thiago Santos; OLIVEIRA, Adriana Marques de; DOMINGOS, Diane Araújo. A ressignificação curricular possibilitada por meio da temática dos agrotóxicos: um processo de compreensão do contexto para a Educação do Campo. Currículo sem Fronteiras, v. 18, n. 2, p. 691-718, maio/ago. 2018.

FREIRE, Paulo. Pedagogia da autonomia: saberes necessários à prática educativa. São Paulo: Paz e Terra, 1996.

FREIRE, Paulo. Pedagogia da indignação: cartas pedagógicas e outros escritos. São Paulo: UNESP, 2000.

GUIMARÃES, Mauro. A formação de educadores ambientais. 2. ed. Campinas: Papirus, 2005.

MARIANI JÚNIOR, Rafael. O estudo de Ecologia no Ensino Médio: uma proposta metodológica alternativa. 2008. 165f. Dissertação (Mestrado em Ciências) - Universidade Católica de Minas Gerais, Belo Horizonte, 2008.

LAKATOS, Eva Maria; MARCONI, Maria de Alexandre. Fundamentos da metodologia cientifica. 6. ed. São Paulo: Atlas, 2011.

LIGNANI, Leonardo de Bem; AZEVEDO, Maicon Jefesson da Costa. "Casa" de quem? História Ambiental e o ensino de Ecologia. In: IX Encontro Nacional de Pesquisa em Educação em Ciências - IX ENPEC. Anais... Águas de Lindóia (SP), nov. 2013. p. 01-08.

LIMA, Maria da Glória Soares Barbosa; MELO, Raimunda Alves. Currículo e articulação de saberes na escola do campo. In: VI Encontro Inter-Regional Norte, Nordeste e Centro-Oeste sobre Formação Docente para a Educação Básica e Superior e I Encontro Internacional sobre a Formação Docente para a Educação Básica e Superior (INTERFOR): Formação, Currículo e Avaliação: Territórios referenciais para a profissão docente. Anais... Brasília: UNB, 2015. v. 01. p. $01-14$.

MACIEL, Eloisa Antunes; GÜLLICH, Roque Ismael da Costa; LIMA, Daniele de Oliveira de. Ensino de Ecologia: concepções e estratégias de ensino. VIDYA, Santa Maria, v. 38, n. 2, p. 21 36, jul./dez., 2018.

MAIA, Alexandre Gori. Valoração de Recursos Ambientais. 2002. 131 f. Dissertação (Mestrado em Desenvolvimento Econômico, Espaço e Meio Ambiente) - Instituto de Economia. Universidade Estadual de Campinas, Campinas, 2002.

MARTINS, Eliecília de Fátima. Extensão como componente curricular: oportunidade de formação integral e de solidariedade. Ciências \& Cognição, Rio de Janeiro, vol. 13, n. 2, p. 201 2-09, jul., 2008.

MATTOS, Ana Dantas Mendez. Valoração ambiental de áreas de preservação permanente da micro-bacia do ribeirão São Bartolomeu no Município de Viçosa, MG. Rev. Árvore, vol. 31 n. 2, p. 347-353, 2007.

MOTOKANE, Marcelo Tadeu. Ensino de Ecologia: as diferentes práticas dos professores. 2000. 264 f. Dissertação (Mestrado em Educação) - Universidade de São Paulo, São Paulo, 2000. 
MOTOKANE, Marcelo Tadeu; TRIVELATO, Silvia Luzia Frateschi. Reflexões sobre o ensino de Ecologia no Ensino Médio. In: II Encontro Nacional de Pesquisa em Educação em Ciências. Anais... Valinhos (SP), 1999, p. 01-11.

NASCIMENTO, Elimar Pinheiro do. Trajetória da sustentabilidade: do ambiental ao social, ao social ao econômico. Estudos avançados, São Paulo, vol. 26, n. 74, p. 51-64, 2012.

ODUM, Eugene; BARRETT, Garry W. Fundamentos de Ecologia. São Paulo: Cengage Learning, 2008.

OLIVEIRA, Otávio José de; CASTRO, Rosani de. Estudo da destinação e da reciclagem de pneus inservíveis no Brasil. In: XXVII Encontro Nacional de Energia de Produção: A energia que move a produção: um diálogo sobre integração, projeto e sustentabilidade. Anais eletrônicos... Foz do Iguaçu, Paraná, out., 2007, p. 01-09.

OROZCO, Yonier Alexander. O ensino da biodiversidade: tendências e desafios nas experiências pedagógicas. Góndola, Enseñanza y Aprendizaje de las Ciencias, Bogotá, vol. 12, n. 2, p. 173-185, jul./dez., 2017.

ROOS, Alana; BECKER, Elsbeth Leia Spod. Educação Ambiental e sustentabilidade. Revista Eletrônica em Gestão, Educação e Tecnologia Ambiental, Santa Maria, v. 5, p. 857-866, 2012.

ROSSET, Peter. A territorialização da Agroecologia na disputa de projetos, e os desafios para as escolas do campo. In: RIBEIRO, Dionara Soares; TIEPOLO, Elisione Vitória; VARGAS, Maria Cristina; SILVA, Nivia Regina (Orgs.). Agroecologia na Educação Básica: questões propositivas de conteúdos e metodologia. 2. ed. São Paulo: Expressão Popular, 2017. p. 117-126.

SADAVA, David et al. Vida: a ciência da Biologia. Trad. Carla Denise Bonan et al. 8. ed. Porto Alegre: Artmed, 2009.

SANTOS, Raimundo Nonato de Melo. Agrotóxicos e Agroecologia no Ensino de Ciências: pesquisa na Escola Família de Miguel Alves, PI. 2018. 33 f. Monografia (Licenciatura em Educação do Campo - Ciências da Natureza) - Centro de Ciências da Educação. Universidade Federal do Piauí, Teresina, 2018.

SILVA, Miriam de Castro. Ensino de Ecologia: dificuldades encontradas e uma proposta de trabalho para professores dos Ensinos Fundamental e Médio de João Pessoa, PB. 2012. 63 f. Monografia (Licenciatura em Ciências Biológicas) - Universidade Federal da Paraíba, João Pessoa (PB), 2012.

SILVA, Maria Sueleuda Pereira da; LIMA, Elmo de Souza. Práticas educativas no contexto da educação do campo: as possibilidades de transformação social. In: LIMA, Elmo de Souza; MELO, Keyla Rejane Almeida (Orgs.). Educação do campo: reflexões políticas e teóricometodológicas. 2016. p. 113-138.

SILVA, Maria do Socorro Ferreira; SILVA, Edimilson Gomes da. Laboratório de ensino em Geografia. São Cristóvão: Universidade Federal de Sergipe; CESAD, 2010. 
SILVEIRA, Sara Pospichil; STUANI, G. M.; CONFORTIN, Ana Cristina. A ressignificação do conceito de Biodiversidade em um Museu de Ciências Naturais. Revista de Ensino de Biologia da Associação Brasileira de Ensino de Biologia (SBEnBio), v. 7, p. 6812-6820, 2014.

SOUZA, João Carlos de. A relação do Homem com o meio ambiente: o que dizem as leis e as propostas de educação para o meio ambiente. Revista Brasileira de Direito Constitucional RBDC, São Paulo, n. 13, p. 107-139, jan./jun., 2009.

SOUZA, Iael de; AZEVEDO, Ryan Ribeiro de. Estudo, estudar, ser estudante no Ensino Superior: condições gerais imanentes e contexto socioeconômico cultural das classes populares. Revista Labor, Fortaleza, vol. 01, n. 16, p. 112-136, 2016.

TEIXEIRA, Mylene Nogueira. O sertão semiárido: uma relação de sociedade e natureza numa dinâmica de organização social do espaço. Revista Sociedade e Estado, Brasília, vol. 31, n. 3, p. 769-797, set./dez., 2016.

TIRIBA, Léa. Crianças da Natureza. In: I Seminário Nacional: Currículo em Movimento: perspectivas atuais. Anais... Belo Horizonte: Universidade Federal de Minas Gerais, nov. 2010. p. 01-20.

TOWNSEND, Colin; BEGON, Michael; HARPER, John. Fundamentos em Ecologia. 3. ed. São Paulo: S. A. Fromthe Original English Language Version, 2010. 